\title{
Harnessing State-of-the-art Internet of Things Labs to Motivate First-year Electrical and Computer Engineering Students
}

\section{Dr. David John Orser, University of Minnesota}

David Orser received his B.S. degree in electrical engineering from Minnesota State University, Mankato, MN, USA in 2000, his M.S. degree and his Ph.D. degree in electrical engineering at the University of Minnesota, Minneapolis, MN, USA in 2007 and 2014 respectively. He is an assistant teaching professor at the University of Minnesota, where his focus is teaching circuits, IoT, and power electronics. He has worked in the high-speed analog IC design industry for IBM and Broadcom for over ten years. He holds five US patents, several publications, and has circuits in over a billion chips around the world. His current research interests include laboratory teaching pedagogy, matrix converters in electric drives, and the application of power electronics in HVDC power systems.

\section{Mr. Kia Bazargan, University of Minnesota}

Kia Bazargan is an Associate Professor with the Department of Electrical and Computer Engineering at the University of Minnesota. Has has published over 70 peer-reviewed papers and book chapters related to FPGAs and VLSI computer-aided design. He received his Bachelors degree in Computer Science from Sharif University, Tehran, Iran, and the MS and PhD degrees in Electrical and Computer engineering from Northwestern University, Evanston, Illinois, in 1998 and 2000, respectively. He has served as an associate editor of the IEEE Transactions on CAD of Integrated Circuits and Systems, and as a guest coeditor of the ACM Transactions on Embedded Computing Systems Special Issue on Dynamically Adaptable Embedded Systems. He has served on the technical program committee of a number of IEEE/ACM sponsored conferences (e.g., Field Programmable Gate Array (FPGA), Field Programmable Logic (FPL), Design Automation Conference (DAC), International Conference on Computer-Aided Design (ICCAD), and Asia and South Pacific DAC). He served as the program chair of the FPGA'18. He has received a US National Science Foundation (NSF) Career Award.

\section{John Sartori, University of Minnesota}

John Sartori received the B.S. degree in electrical engineering, computer science, and mathematics from the University of North Dakota, Grand Forks and the M.S. and Ph.D. degrees in electrical and computer engineering from the University of Illinois at Urbana-Champaign. He is currently a professor of Electrical and Computer Engineering at the University of Minnesota, Twin Cities. His research focuses on computer architecture, computer aided design, embedded systems, and algorithm development, especially focused on energy-efficient computing, high-performance computing, stochastic computing, and application-aware design and architecture methodologies. John's research has been recognized by multiple best paper awards, an NSF CAREER award, and has been the subject of several keynote talks and invited plenary lectures. His work has been chosen to be the cover feature for popular media sources such as BBC News and HPCWire, and has also been covered extensively by scientific press outlets such as the IEEE Spectrum, IEEE Micro, and the Engineering and Technology Magazine. 


\title{
Harnessing State of the Art Internet of Things Labs to Motivate First-Year Electrical and Computer Engineering Students
}

\begin{abstract}
Engineering is about improving people's lives by creating solutions to real-world problems. There is a need, especially in diverse populations, to show first-year students that calculus and physicsbased skills can be leveraged to create these solutions. Recently, the Internet of Things (IoT) movement has driven a cost reduction in intelligent network connected devices. IoT devices provide an accessible platform for using engineering to solve new and exciting real-world problems. It is hoped that by teaching the skills to connect electronics, programming, social media, and phonebased control with real-world physical solutions, students will gain a glimpse of the possibilities an engineering education provides. In addition, these useful and relevant skills may lead to heightened interest, motivation, diversity, and retention in Electrical and Computer Engineering (ECE) students.

This work details the creation, implementation, and evaluation of an IoT Lab Module in a firstyear introductory $\mathrm{C}++$ programming course. The Particle Photon WiFi-enabled micro-controller platform which utilizes Arduino-like embedded-C programming, API-driven cloud functions, and a web-based development environment to provide a low-cost low-complexity IoT platform. The lab module consists of four hardware-based exercises. In addition to fundamental programming skills, students are taught to use sensors, actuators, and cloud communication, including integration with Google Docs, text messaging, and social media. Using class content and a system of online, selftaught "device descriptions" and "quick lessons", students submit project proposals and develop an IoT-based project. Student projects include a Google calendar-based alarm clock where the user must solve a challenge before silencing the alarm. Other projects included smart parking, home security, plant care, and a web-based automated brewing system. At the end of the semester, students showcase their projects to faculty, staff, and other students.

The IoT lab module was created to improve interest, motivation, diversity, and retention of students in ECE. Interest and motivation are tracked by University-wide Student Rating of Teaching (SRT) surveys. The results show a greater than one standard deviation improvement in student survey scores over a period of five semesters. In addition, course enrollment has risen. Retention of students (including diversity of retained students) will be evaluated when sufficient data are available.
\end{abstract}




\section{Introduction}

Advances in chip design and a large community of developers have resulted in relatively cheap hardware platforms with a plethora of software libraries for emerging Internet-of-Things (IoT) technology. Given the market demand and the large application domains that can benefit from IoT, having skills to implement such systems will be valuable for the Electrical and Computer Engineers of tomorrow.

Many recently developed courses implement smart devices (microcontrollers and single-board computers) that can sense inputs, make decisions, and actuate outputs. These include the Raspberry Pi, Beagle Bone ${ }^{1}$, Arduino ${ }^{23}$, and Embedded $\mathrm{ARM}^{4}$. One reported concern of students that drop out of ECE, especially underrepresented students, is the feeling of being overwhelmed and intimidated by electronics and programming ${ }^{3}$. The use of these hobbyist-level devices (Pi, Beagle Bone, Arduino), with their excellent on-line resources and low barrier to entry, makes excellent choices for lower division courses.

Taking the step from smart devices to IoT devices requires networked communication. Some courses utilize a secondary system (like a smartphone) to enable this internet-level communication $^{25}$. Far fewer courses provide for direct networked internet communications of the IoT devices, and those are often offered only at a senior level ${ }^{6}$. This lab uses the Particle Photon, which is an Arduino-like device.

This work reports on the implementation of an IoT lab module in an ECE-oriented freshman-level $\mathrm{C}++$ programming course at the University of Minnesota. The 15-week course consists of three one-hour lectures and one three-hour lab session per week. The lab sessions are split between $\mathrm{C}++$ programming labs and the IoT labs. The IoT labs are organized into four one-week labs covering device setup, input/output devices, cloud connectivity, and simple multitasking. The labs are followed up with a major project taking between three and six weeks to complete depending on the preferences of the faculty teaching the course. A final project showcase featuring IoT solutions to student-defined problems is held in the last week of class. The IoT-based lab includes an accessible development environment, a structured lab delivery, and a layered learning environment to further enhance the retention of students within ECE.

We have used qualitative and quantitative measures to evaluate the success of the lab modules. Qualitative measures include anecdotal evidence and student evaluation of the course. The quantitative analysis is performed by measuring the improvement of student grades in a follow-on course. Our long-term plans are to disseminate our experience, expand the target audience, and publicly release the lab manuals and supporting documents (link to the labs omitted for the blind review process).

\section{Goals}

Below, we outline our motivations for creating the IoT course module. First and foremost, our goal for this course module was to engage students by connecting programming and electrical design skills to meaningful, real-world impacts. Student engagement increases when they can directly 
envision how the skills they are learning can enable them to do something of value and make an impact in the world. The IoT course module makes those possibilities readily apparent. Students give more value to the programming and electrical design skills they learn, as they see how they can be applied in real-world scenarios. Furthermore, students find that even at the onset of their ECE learning experience, with no prior skills necessary, they can gain access to powerful tools. Most students enter the course with no experience in electronics or programming, and they leave being able to design complete IoT systems that are both useful and creative. Students feel that they are getting something valuable out of the course, and in turn, they see the value of being in the ECE program. They also learn a new way to solve problems and develop interesting solutions. Now, students become ambassadors for our program, generating interest as they show others what they can do in ECE.

Besides generating interest in ECE and engaging students in the learning process, the IoT design skills that students learn are in high demand in the workforce. The Internet of things is growing at an exponential rate. Most estimates project the number of IoT devices to reach 100 Billion by $2020^{7 / 819}$. At this time, IoT is a relatively new area and IoT design skills are not taught at many universities. Giving students this background equips them to gain opportunities that others in their cohort may not have. Training students to meet the market demands for IoT technology establishes our university at the forefront of a big socioeconomic trend, with the hope that our students will benefit and become leaders in this area.

Another goal of the IoT course module is to provide a project-based learning experience for students. Today's engineering students must solve tomorrow's challenging problems in a world that is evolving faster and facing more critical challenges than ever before ${ }^{10}$. Engineering education must evolve in order to prepare engineers who will be able to assess and solve these challenges. Research suggests that project-based experiential learning is an effective strategy to engage students ${ }^{1}$. Research-oriented knowledge-building opportunities throughout an engineering curriculum solidifies their interest in engineering and self-motivated learning improves educational outcomes 11112 .

Research shows that project-based learning experiences have more impact when they are extended

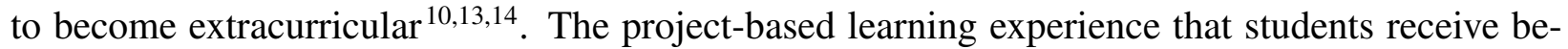
comes an on-ramp for complex and interesting projects throughout the course of their academic careers and beyond. Students are encouraged to continue promising projects initiated in their introductory courses by leveraging resources available at the university such as seed funding for studentled projects and makerspaces that provide tools and resources to support project work.

\section{Structured Labs}

The Photon from Particle ${ }^{1}$ is an Arduino-compatible development board with wifi-enabled cloud features (see Fig. 1 - a). The board is an ideal platform for an introductory course that allows students to work on interesting and real-life projects. The lab module is organized into four progressively more advanced labs (see Fig. 1 -b).

\footnotetext{
[http://particle.io
} 


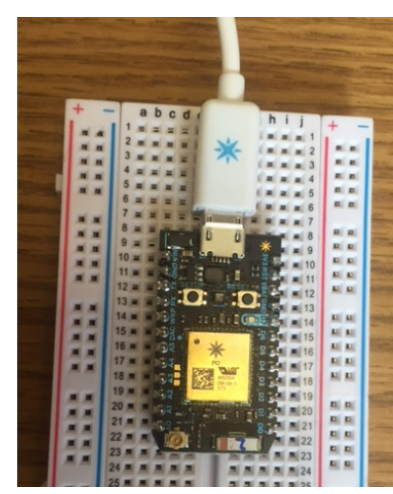

(a)

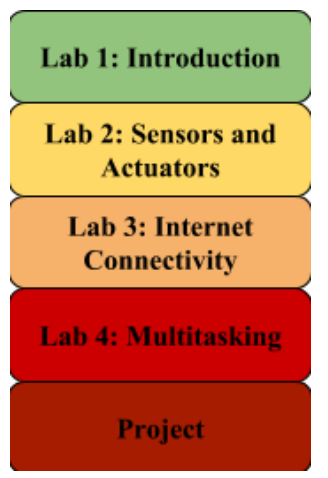

(b)

Figure 1: (a) The Particle Photon on a breadboard. (b) The structure of the labs. The tones of red show progressively more challenging labs that require more independence from students.

The labs are described below. They progressively become more challenging and open to creative problem solving, requiring students to show more independence as their skill set expands.

- Lab1 - Introduction to the Particle Photon: A step-by-step guide that walks students through the setup process to register their boards and set them up with wifi credentials to enable them to connect to the cloud.

- Lab2 - Sensors and Actuators: The lab starts by showing students how to use a light sensor, reading analog voltages on an input pin on the board. Then students are asked to design the circuit and write programs to interface with other sensors, both analog (temperature sensor) and digital (push button). Students also learn to use output devices. The lab has walk-through instructions on how to use RGB (Red, Green, Blue) LEDs (see Fig. 2). After learning about how to interface with sensors and actuators, students are asked to come up with "mini-projects" that utilize different sensors and actuators, for example, a music box that plays a song or a multi-tone siren when the user presses a button. Lab 2 is 14 pages long.

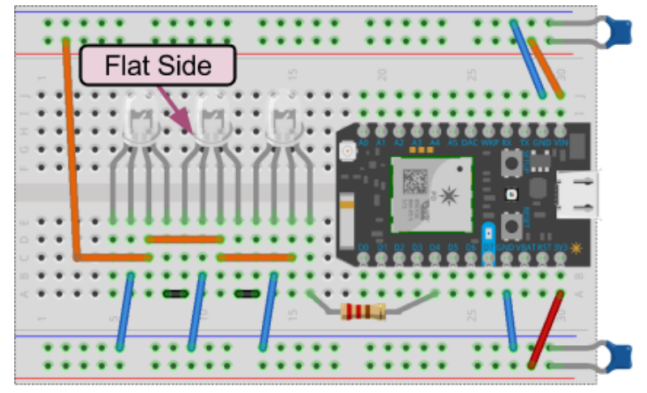

Figure 2: The RGB LED circuit.

- Lab3 - Internet Connectivity: This 22-page lab teaches the basics of HTML and Javascript and shows students how to interface to their program and circuit via the Internet. They learn to remotely view the data gathered by the device or send "commands" by remotely invoking functions in their program. They can create simple web pages that allow any user in the 
world (with the right password) to control devices connected to their circuit (e.g., turn on and off a fan or control a robot). Furthermore, students learn how to connect to the Cloud and interact with services such as weather.com or log the values read by various sensors in a Google spreadsheet. They learn how to write programs to trigger events in the real world (such as sending a text message to their phone) when certain conditions are met in the environment in which their circuit operates (e.g., when the humidity sensor placed in the soil of their favorite plant senses that conditions are too dry). For such actions, we use the popular service IFTTT (IF This, Then That), which interfaces with many cloud services ${ }^{2}$ This lab also asks students to work on a "mini-project" of their choosing.

- Lab4 - Simple Multitasking: This 12-page lab shows students how to perform multiple tasks at the same time. For example, a program must be able to blink an LED at regular intervals, while at the same time check to see if the user has pressed a button to change the blinking rate. Performing such tasks is easy in more advanced programming environments that natively support multi-threading or interrupts (technical terms for multi-tasking), but implementing them on a simple platform such as the Photon board requires a few programming tricks to mimic true multi-tasking.

\section{A Layered Learning Environment}

The labs are designed with a layered learning environment model in mind. Students are exposed to new topics gradually, while requiring and refreshing previously covered materials. Each lab has a pre-lab that is supposed to be done before arriving in the lab. The pre-lab covers background material and basic tasks that help ease students into the concepts that will be used during the actual lab. Pre-lab exercises are usually written with detailed explanations and step-by-step guides. The main lab procedure covers more complex examples, which might require the help of a TA or an instructor. Finally, the lab ends with a unguided mini-project or problem the student has to complete with limited guidance. The post-lab reports help students recall and summarize what they have learned and organize their thoughts. Students demonstrate working components of each lab to the teaching assistant and are graded on question/answers during the demo. The final project and post-lab reports provide accountability and testing of conceptual knowledge.

Each lab also features many linked supplementary documents. These include:

- Background docs - In-depth background materials and advanced learning resources

- Quick lessons - short single topic documents

- Device descriptions - simplified datasheet-like documents with small working examples

\section{Continual Improvement}

The labs are written as Google documents. All the teaching assistants (TAs) and instructors have edit access. Students are provided a link to the live document, i.e., with all the latest changes. They

$\sqrt[2]{\text { https://ifttt.com/ }}$ 
do not see comments that the instructors and the TAs have added as to-do items and suggestions for future improvements. Alongside the lab manuals, there are accompanying documents written for the TAs. They list solutions to questions in the lab manuals, working example code segments, and common pitfalls. The latter is particularly important, as it catalogs the common mistakes students make when wiring up their circuits or writing their code. It allows the TAs to debug students' work quickly and more efficiently help them learn the material.

\section{Final Project}

A significant goal previously mentioned for this lab is to provide a project-based learning experience for students. The next three sections of this work focus on the methods employed to create this experience. The first, Guided Development of Projects, reviews the project requirements and the process students go through to develop a problem that is challenging, interesting and has a feasible solution. The second, Project Resources, reviews the physical hardware provided to the students to implement these solutions as well as the rough costs associated with the components. Finally, the Internet of Things Project Showcase reviews the implementation of the final presentation of the project to peers and faculty.

\section{Guided Development of Projects}

Guiding first-year students to develop projects that are interesting and attainable, yet challenging takes a significant amount of planning and effort. Before students can settle on a problem, we need to explore the types of tools that will be available to them. Each of the labs addresses a major functional area of IoT and micro-controllers (as outlined in detail above.) The micro-projects in the core labs provide students opportunities to implement operational hardware and software for one of several optional devices included in the lab kit. When students browse the list of optional components, it allows them see broadly what is possible, even if they do not explicitly use every component that is available as part of the labs.

Once students are familiar with the capabilities of the micro-controllers, sensors, actuators, and the communication tools provided by the Particle Cloud Service and IFTTT, students are provided with the project requirements. Project requirements attempt to focus the projects into the IoT space yet remain very open-ended.

Projects must:

- Sense changes in the environment

- Actuate changes in the environment

- Communicate via the Internet

One of the recurring themes of IoT is the idea that small connected devices can make smart decisions utilizing both local and global information sources. These requirements help keep the projects focused on the intelligent processing of information (both local and global) to influence 
the physical world. Lastly, projects should be fun and exciting. This aids student motivation, learning, and retention.

The requirements above are necessary but not sufficient to guide students to exciting, attainable, and challenging projects. This is especially true for students from under-represented populations. Specifically, students that are less familiar with "geeky" hobbies (like robotics, Arduino, graphical programming, etc.) need to be encouraged to think big and guided towards tools that will facilitate solutions to the problems students wish to address. Rose et al. mentions the importance of a guided interactive process to develop successful projects ${ }^{15}$.

Students are first provided with a project description document and a short in-class lecture covering the requirements and emphasizing the importance of making the project something that is personally fun, interesting, and exciting to the student proposing the project.

The in-class discussion is followed by a students submitting a concise project proposal (1 paragraph) and a short presentation/pitch (less than 3 minutes). Several professors and teaching assistants review the proposals and submit feedback on the projects. These comments are designed to guide some projects towards a manageable scope while pushing other projects to stretch students' skills. Students are then free to respond to the comments and adjust their proposals.

\section{Project Resources}

It is a goal of this course to provide students with all the tools necessary to work independently. This is done not to reduce the burden on university resources, but instead to provide opportunities for students to learn beyond the course. In contrast, to keep projects fresh and exciting, it is essential to offer a wide variety of IoT components that can be added to the Photon microcontroller. To balance these conflicting objectives, the lab components are broken into three categories a Student Lab Kit (purchased with course fees, kept by the student), Group Lab Kit (owned by the ECE department), and optional student-purchased components. The three-tiered structure helps to keep costs below $\$ 50$ per student while providing an extensive range of components and capabilities for the projects.

The Student Lab Kit consists of everything a student needs to complete the four core labs. The kit includes necessary prototyping hardware, like a breadboard, wires, resistors, pliers, etc. Also, some inexpensive IoT components are provided for students to experiment with on their own. The student lab kit is portable and complete; no fixed lab equipment, other than a personal PC, is required for students to create functional IoT devices. We hope this provides substantially expanded opportunities for students to "tinker" on their own time.

The Group Lab Kit is a selection of medium cost components (less than \$20 each) that students can borrow for personal exploration or inclusion in projects. One of these group kits is maintained for each section of the course (5-10 sections per semester). The quantity of each part in this kit is limited (usually 2-4), and parts are provided to students on a first come, first served basis. These kits are refreshed (due to lost items, broken parts, etc.) at the end of each semester. The initial capital cost of these kits was around $\$ 700$ (for 5 lab sections of 15 students each) with some minimal cost in restoring the kits each semester. 
Finally, students are encouraged to utilize common IoT/Robotics hobbyist websites (adafruit.com, pololu.com, sparkfun.com, etc.) to find original components to add to their projects. Students are encouraged to limit the amount they spend to less than $\$ 40$. Generally speaking, students seem very excited to contribute small amounts to make their projects more useful and unique. The students' efforts have the added benefit of providing the department with a list of attractive and reasonably-priced components that can be used to update the group kit over time. It is through the combination of these three tiers of components that students can implement an extensive range of projects.

\section{Internet of Things Project Showcase}

Student projects are presented in an Internet of Things Project Showcase held in the public atrium of the ECE and CS building and rated by a selection of faculty and teaching assistants. Students prepare a 30-second demonstration of their project and are available to answer questions from visitors and their professors.

The project showcase has a number of advantages. First, the showcase creates a sense of obligation to produce a functional and exciting project. The showcase also serves as a useful recruitment tool for generating interest in ECE. Prospective students who visit the show and learn about the fascinating projects that introductory-level ECE students have created become excited about ECE. Students in the show also become passionate about ECE, as they survey their accomplishments, new skills, and how far they have advanced through one ECE course. Students also get a feel for what a senior design project showcase is going to be like, as well as an opportunity to meet more senior students and faculty outside

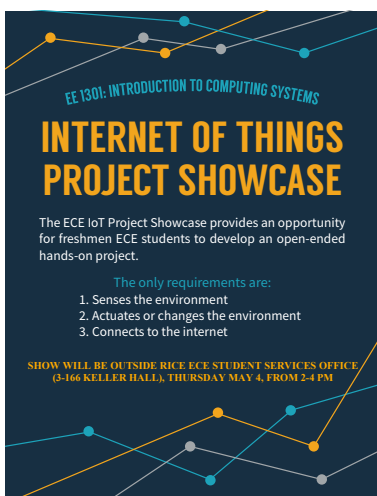

Figure 3: Advertisement for IoT project showcase. of class.

\section{Project Results and Evaluation of the Course}

The response to the development and implementation of this course change was overwhelmingly positive. Three main areas show that the impact of this course change provided significant benefits. First, anecdotal evidence, both from faculty that have taught the course since the changes were introduced and from students who have taken the course indicates that our goals are being achieved. Second, Student Rating of Teaching (SRT) responses show a positive trend. These are standard Likert-type evaluations provided to all students at the end of a course. Third, tracking student grade performance in the follow-on course Introduction to Micro-controllers, which develops the low-level programming skills necessary to implement the simplified libraries available in this lab, shows evidence of better student outcomes. 


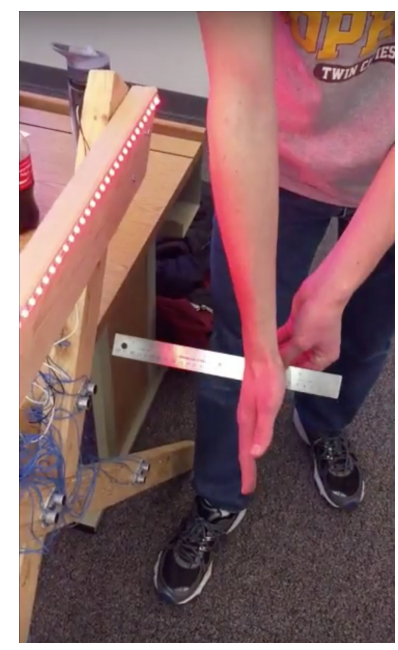

(a)

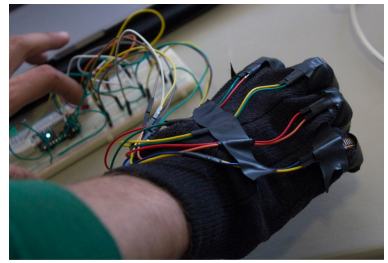

(b)

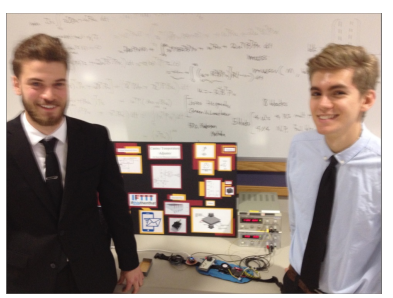

(c)

Figure 4: (a) A parking sensor project demonstration. (b) A wearable glove that translates sign language into text messages. (c) Students present a wearable pet health monitor project to the public at an IoT project showcase.

\section{Anecdotal Evidence}

Students are clearly excited about the new labs. Each semester, a number of students write in their course evaluation forms that they learned much more through their lab work than they learned in lectures. A student wrote "I wish we had spent $90 \%$ of our time doing labs and projects and only $10 \%$ lectures on C++". A number of students each semester indicate that because of this course, they decided to switch majors to Computer Engineering.

Professors report that students are much more motivated and feel more connected to the material they are learning. They have provided unsolicited feedback that they enjoy teaching the course much more in its new format. The project showcases create a lot of "buzz" in the department and are sources of excitement, lively interactions, and inspiration for other students. Fig. 4 shows a few examples of project demos during a project showcase.

Unsolicited feedback from students provides additional anecdotal evidence that the goals for the IoT course module are being met. For example, one student from the class who designed a wearable glove that translates sign language into text messages (Figure 4(b)) was encouraged to develop his course project further as an extracurricular activity. After completing the course, the student successfully applied for project funding made available by the ECE department, allowing him to learn advanced machine learning techniques and incorporate them into his IoT device, along with a new, more mobile form factor. He was later encouraged to participate in an IoT hacking event where he garnered notice from an IoT company. This led to him receiving a job as an IoT and machine learning developer. Encouraged by his success, which he attributed to his learning experience that began in the IoT course, he stated that without the course "I would not have gotten interested in IoT or machine learning, started MKono (the hobby project you encouraged me to start), or known about IoTHackDay, ... I have you to thank for this job." 


\section{Student Evaluations}

We utilized the University of Minnesota standard Student Rating of Teaching surveys to determine if student interest and motivation changed. Every course is required to complete these anonymous questionnaires, resulting in excellent student survey response rates. The questions in the forms do not directly measure student learning of a particular subject matter but instead focus on the relative perceived quality of the course. The five course-related questions provided to students were:

1. I have a deeper understanding of the subject matter as a result of this course.

2. My interest in the subject matter was stimulated by this course.

3. Instructional technology employed in this course was effective.

4. The grading standards for this course were clear.

5. I would recommend this course to other students.

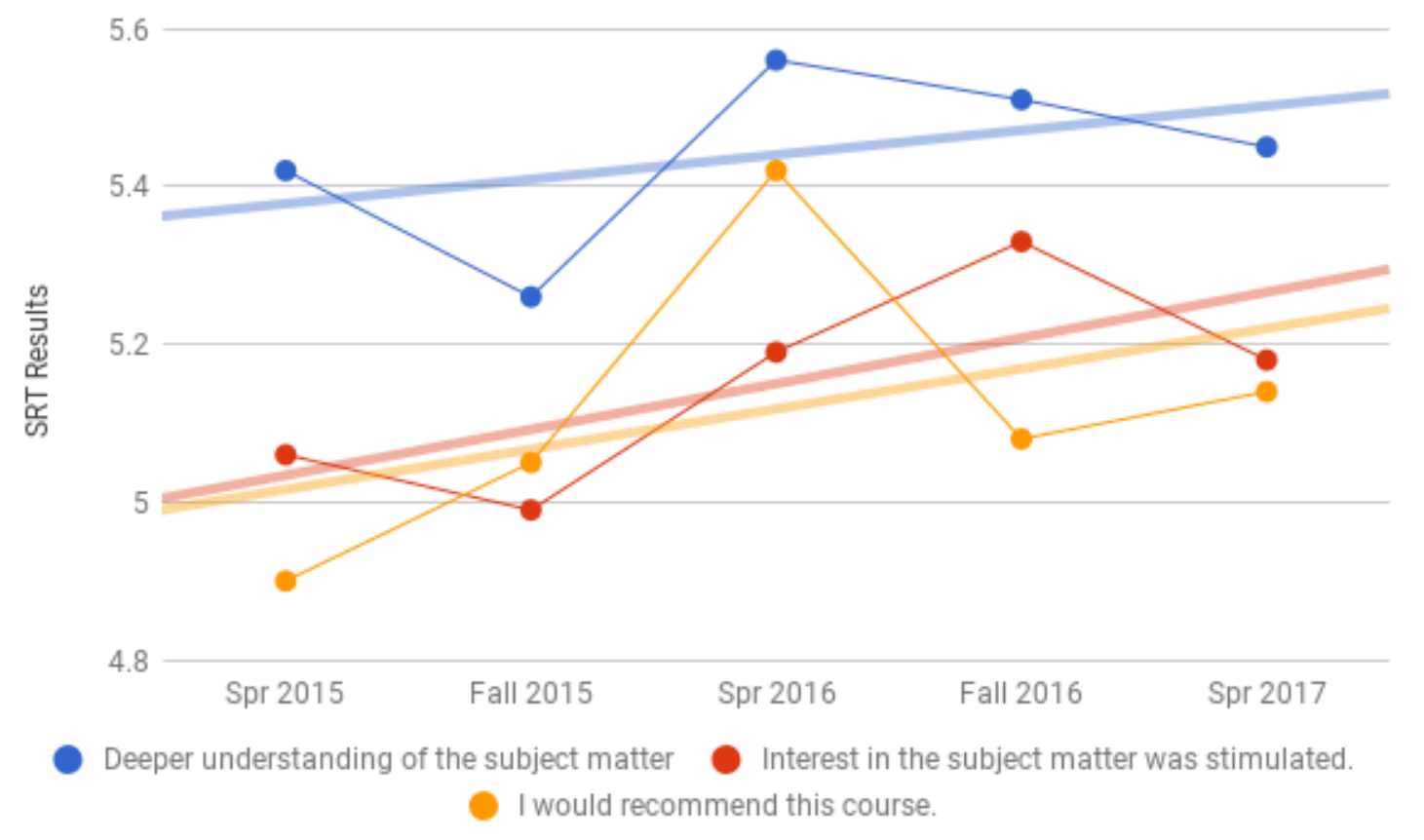

Figure 5: Student Rating Of Teaching responses show positive trends beginning at the time that the IoT course module was introduced.

(Other sections of the survey cover the classroom and professor performance.) Questions \#1, \#2, and \#5 are the most relevant to this analysis. A period of 5 semesters is reported in the bottom half of Fig. 6, a more extended period is not available due to a change in the questionnaire format in the Fall of 2015. These results are plotted along with a least-squares linear fit in Fig. 5. One can see a positive trend. Comparing the slope of this line to the adjusted standard deviation of the survey responses shows a greater than one standard deviation improvement in the course over the five semesters shown. It should be noted that it is likely a decrease in the course evaluations was 
shown during the first semester of implementation (Fall 2015). This may be attributed to the fact that the IoT course module was not fully embedded in the course with supporting lectures until the next semester (Spring 2016). The course lectures were updated in Spring 2016 to support the new course structure.

\begin{tabular}{|c|c|c|c|c|c|c|c|}
\hline \multirow[b]{3}{*}{ ID } & \multicolumn{3}{|c|}{ LSQ 5-term Net Chg } & \multirow{2}{*}{$\begin{array}{l}0.16 \\
0.10\end{array}$} & \multirow{2}{*}{$\begin{array}{l}0.29 \\
0.09\end{array}$} & \multirow{2}{*}{\multicolumn{2}{|c|}{$\begin{array}{l}0.25 \\
0.17\end{array}$}} \\
\hline & & & Adj Std Dev & & & & \\
\hline & Term & $\begin{array}{l}\text { IoT } \\
\text { Mod }\end{array}$ & Instructor & $\begin{array}{l}\text { Deeper } \\
\text { understanding of } \\
\text { the subject matter }\end{array}$ & $\begin{array}{l}\text { Interest in the } \\
\text { subject matter was } \\
\text { stimulated. }\end{array}$ & $\begin{array}{l}\text { I would recommend } \\
\text { this course. }\end{array}$ & $\begin{array}{l}\text { Class } \\
\text { size }\end{array}$ \\
\hline 1 & Spr 2015 & No & Prof 1 & 5.42 & 5.06 & 4.9 & 48 \\
\hline 2 & Fall 2015 & Yes & Prof 1 & 5.26 & 4.99 & 5.05 & 86 \\
\hline 3 & Spr 2016 & Yes & Prof 2 & 5.56 & 5.19 & 5.42 & 63 \\
\hline 4 & Fall 2016 & Yes & Prof 1 & 5.51 & 5.33 & 5.08 & 77 \\
\hline 5 & Spr 2017 & Yes & Prof 3 & 5.45 & 5.18 & 5.14 & 56 \\
\hline
\end{tabular}

Figure 6: Student Rating Of Teaching Responses

\section{Quantitative Analysis Based on Grade Point}

Students who take our introductory $\mathrm{C}++$ course, move on to take a more advanced Introduction to Microcontrollers course. As a measure of success, we have looked at the grades of students in the follow-on course to see if there is a noticeable difference in their performance before and after the new labs were introduced. Fig. 7 plots the average grade point of the follow-on course against the semester the students took the introductory $\mathrm{C}++$ course. The vertical red line shows when the new labs were deployed. The dashed line shows the average before (2.92) and after (3.04) the new labs were deployed. The fluctuations on each side are a result of different grading standards used by the professors who taught the follow-on course. Despite the variation, there is a marked increase in the performance of the students who have gone through the new labs. 


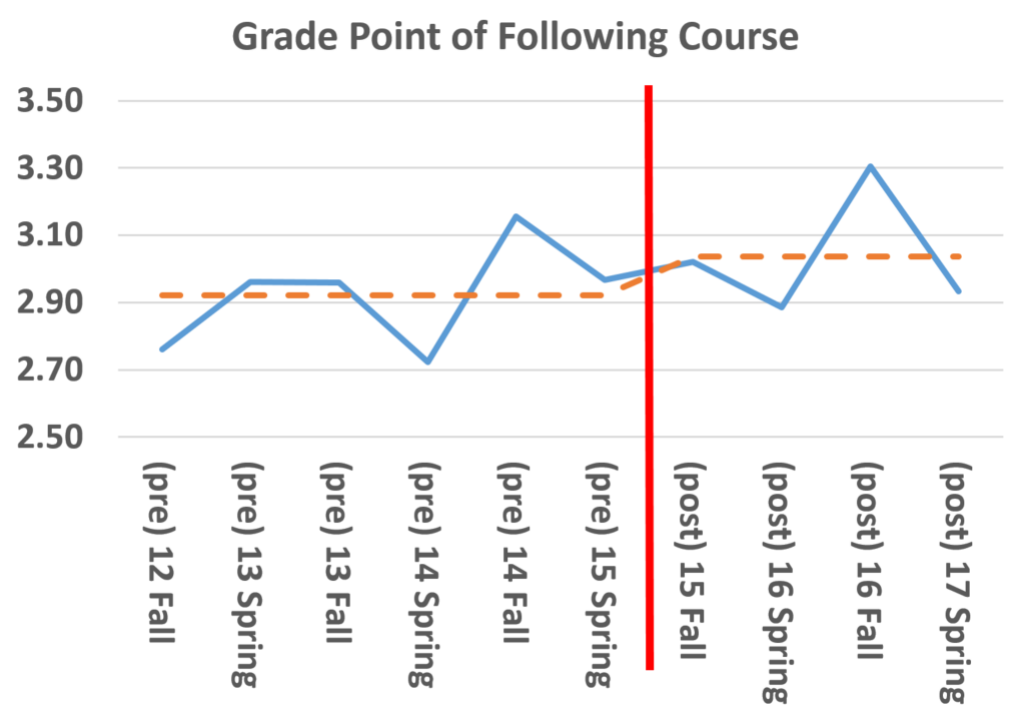

Figure 7: Grade point of students in a follow-on course (Intro to Micro-controllers) that have taken the course with our labs (ECE C++). The vertical solid red line marks the semester when the new material was introduced. The dotted line shows the average grade point before and after the change.

\section{Conclusion and Future Work}

We have developed a set of labs and supporting documents that enable students to understand and implement fully-functional IoT devices. Student feedback and performance shows that we have been successful in providing an exciting learning environment that helps students develop valuable experience in an emerging field. We would be more than happy to share our labs and documentation with colleagues in academia and the general public.

We are currently working on two offshoots of these labs:

- Freshman 3D Printing + Micro-controllers: We have developed a lighter version of these labs targeting non-ECE freshman. The new labs cover basic programming constructs, working with actuators, and basic Internet connectivity. The labs are currently being taught in one section of the course as part of our early evaluation and beta-testing of the content.

- High school and Middle School: We are also developing another version of the IoT module that targets high school and middle school students. We plan to finish the development of this version over the summer and roll out the beta testing in the fall.

\section{Links to Labs}

EE 1301: Internet of Things Lab Module

- IoT Laboratory Instructions: Overview for Professors and Teaching Assistants 
- IoT Laboratory \#1: Introduction to your Particle Photon

- IoT Laboratory \#2: Getting Started with Sensors and Actuators

- IoT Laboratory \#3: Flying (not so) High in the Cloud

- IoT Laboratory \#4: Simple Multi-Tasking on the Photon

Additional support materials (Quick Lessons, Device Descriptions, TA Notes, etc.) are available by request, please contact David Orser.

\section{References}

[1] Joseph D. Steinmeyer. Project-based Learning with Single-Board Computers. 2015 ASEE Annual Conference \& Exposition, pages 26.1272.1-26.1272.18, June 2015. ISSN 2153-5965.

[2] Girma Tewolde. Innovative Course Modules for Introducing ECE to Engineering Freshmen. 2016 ASEE Annual Conference \& Exposition, June 2016. ISSN 2153-5965.

[3] Charles Carlson and Dwight Day. Transformation of an Introductory Computer Engineering Course Utilizing Microprocessors and a Focus on Hardware Limitations. 2017 ASEE Annual Conference \& Exposition, June 2017.

[4] Dhananjay V. Gadre, Ramesh S. Gaonkar, Nikhilesh Prasannakumar, and Sneha N. Ved. Embedded Systems and Internet of Things (IoTs) - Challenges in Teaching the ARM Controller in the Classroom. 2017 ASEE Annual Conference \& Exposition, June 2017.

[5] Samuel J. Dickerson. Introducing the Internet-of-Things to the Next Generation of Engineers. 2017 ASEE Annual Conference \& Exposition, June 2017.

[6] Nannan He, Han-Way Huang, and Navya Mereddy. Work-in-Progress: Experience of Teaching Internet-ofThings Using TI ARM based Connected Launchpad. 2015 ASEE Annual Conference \& Exposition, pages 26.1766.1-26.1766.12, June 2015. ISSN 2153-5965.

[7] Henry Blodget, Marcelo Ballve, Tony Danova, Cooper Smith, John Heggestuen, Mark Hoelzel, Emily Adler, Cale Weissman, Hope King, Nicholas Quah, John Greenough, and Jessica Smith. The internet of everything: 2015. BI Intelligence, 2014.

[8] Dave Evans. The internet of things: How the next evolution of the internet is changing everything. CISCO white paper, April 2011.

[9] Gil Press. Internet of Things By The Numbers: Market Estimates And Forecasts. Forbes, 2014.

[10] Cynthia J. Atman, Sheri D. Sheppard, Jennifer Turns, Robin S. Adams, Lorraine N. Fleming, Reed Stevens, Ruth A. Streveler, Karl A. Smith, Ronald L. Miller, Larry J. Leifer, Ken Yasuhara, and Dennis Lund. Enabling engineering student success: The final report for the center for the advancement of engineering education. Morgan and Claypool, 2010.

[11] G. D. Kuh, J. Kinzie, J. A. Buckley, B. K. Bridges, and J. C. Hayek. What matters to student success: A review of the literature. Commissioned Report for the National Symposium on Postsecondary Student Success: Spearheading a Dialog on Student Success, 2006. 
[12] M. Baxter Magolda. Making their own way: Narratives for transforming higher education to promote selfdevelopment. Stylus, 2001.

[13] D. W. Knight, L. E. Carlson, and J. Sullivan. Improving engineering student retention through hands-on, team based, first-year design projects. In International Conference on Research in Engineering Education, 2007.

[14] Sheri Sheppard, Shannon Gilmartin, Helen L. Chen, Krista Donaldson, Gary Lichtenstein, Ozgur Eris, Micah Lande, and George Toye. Exploring the engineering student experience: Findings from the academic pathways of people learning engineering survey (apples). Center for the Advancement of Engineering Education, 2010.

[15] Jonathan Rose, Braiden Brousseau, and Alexandra Makos. A Multi-Disciplinary Mobile Applications Project Course at the Graduate Level. In Proceedings of the International Conference on Frontiers in Education: Computer Science and Computer Engineering (FECS), page 141. The Steering Committee of The World Congress in Computer Science, Computer Engineering and Applied Computing (WorldComp), 2015. 